\title{
MEME DE OSWALDO CRUZ COMO ESTRATÉGIA DE ENSINO SOBRE FEBRE AMARELA E A IMPORTÂNCIA DA VACINAÇÃO
}

\author{
Daniela Frey ${ }^{1}$ \\ Maria de Fátima Alves-de-Oliveira² \\ Marcelo Diniz Monteiro de Barros ${ }^{3}$
}

\begin{abstract}
RESUMO
A febre amarela é uma doença grave, prevenida de forma eficiente pela vacinação. Entre 2017 e 2018 o país teve um considerável aumento do número de casos da forma silvestre e de mortes dela decorrentes, especialmente em áreas que não eram consideradas de risco. Nossa proposta foi utilizar, para ir à contramão das fake news que estimulam a não vacinação, um meme com a imagem de Oswaldo Cruz como desencadeador, em aulas de Biologia de um curso Técnico em Telecomunicações Integrado ao Ensino Médio de uma instituição pública, em Petrópolis (RJ), de discussões sobre febre amarela e sua profilaxia, levando a $100 \%$ da cobertura vacinal entre esses alunos. Questões de saúde pública, como essa, podem e devem ser levadas para a sala de aula não apenas de Biologia, mas de forma multidisciplinar, promovendo debates e contribuindo para um movimento de divulgação científica, assim como para a profilaxia desta e de outras doenças.
\end{abstract}

Palavras-chave: Ensino de febre amarela. Linguagem digital e meme. Vacinação. Recurso didático.

\section{MEME OF OSWALDO CRUZ AS A TEACHING STRATEGY ABOUT YELLOW FEVER} AND THE IMPORTANCE OF VACCINATION

\begin{abstract}
Yellow fever is a serious disease, effectively prevented by vaccination. Between 2017 and 2018, Brazil had a considerable increase in the number of cases of wild yellow fever and deaths resulting therefrom, especially in areas that were not considered at risk. In opposition to fake news that stimulate non-vaccination, our proposal was to use a meme with the image of Oswaldo Cruz, as a trigger, in Biology classes of a Technical Course in Telecommunications Integrated to High School of a public institution, in Petrópolis (RJ), of discussions about yellow fever and its prophylaxis, leading to $100 \%$ of vaccination coverage among these students. Public health issues, such as this one, can and should be taken into the classroom, not only in Biology, but in a multidisciplinary way, promoting debates and contributing to a scientific dissemination movement, as well as for the prophylaxis of this and other diseases.
\end{abstract}

Keywords: Teaching yellow fever. Digital language and meme. Vaccination. Didactic strategy.

Recebido em: 29/7/2020

Aceito em: 19/10/2020

\footnotetext{
1 Autora correspondente. Cefet/RJ. Rua do Imperador, 659 - Centro. CEP 25620-003. Petrópolis/RJ, Brasil. http://lattes.cnpq.br/ 4908002612653354. https://orcid.org/0000-0002-9794-327X. danielafrey@hotmail.com

2 Fundação Oswaldo Cruz, Instituto Oswaldo Cruz. Rio de Janeiro/RJ, Brasil. http://lattes.cnpq.br/3047876834714077. https://orcid. org/0000-0002-1906-5643.

3 Pontifícia Universidade Católica de Minas Gerais, Instituto de Ciências Biológicas e da Saúde. Belo Horizonte/MG, Brasil. http://lattes.cnpq. br/3426609037202095.
} 
Um meme $e^{4}$ pode ser utilizado em salas de aula como recurso didático? É possível empregarmos ferramentas digitais para disseminarmos informações corretas a respeito de doenças e sua prevenção? O debate acerca dos movimentos mundiais antivacinação pode ser trazido aos programas escolares? Nossa pesquisa desenvolveu-se a partir da tentativa de responder a essas questões.

Na primeira quinzena de fevereiro de 2018 o número de casos e de mortes pela febre amarela crescia dia a dia no Brasil. Assim, nos propusemos a elaborar uma estratégia de ensino para levar essa temática à sala de aula, visando à sensibilização e à ampliação do conhecimento sobre essa doença (assim como sua prevenção) com nossos estudantes e a comunidade escolar.

Compreende-se estratégia de ensino como "a arte de aplicar ou explorar os meios e condições favoráveis e disponíveis, com vistas à consecução de objetivos específicos" (ANASTASIOU; ALVES, 2015, p. 75-76). Sendo um estrategista, o professor (ou alguém que age como tal, em vista de determinados objetivos em processos de ensinagem) deverá "estudar, selecionar, organizar e propor as melhores ferramentas facilitadoras para que os estudantes se apropriem do conhecimento" (ANASTASIOU; ALVES, 2015, p. 76). Bordenave e Pereira (2018) sublinham que os objetivos do ensino que se pretende sejam estabelecidos da forma mais clara possível. Os autores ressaltam, ainda, a importância de um estado ativo à eficiência da aprendizagem, tanto por parte do professor quanto por parte do aluno. $O$ entusiasmo do professor

pode e deve ser canalizado mediante planejamento e metodologia adequados visando sobretudo a incentivar o entusiasmo dos alunos para realizarem por iniciativa própria os esforços intelectuais e morais que a aprendizagem exige (BORDENAVE; PEREIRA, 2018, p. 60).

Nessa construção didática o professor procura a melhor estratégia de ensino compatível com sua formação pessoal e com seus alunos, assim como com o tema a ser desenvolvido. Segundo Morin (2015, p. 62), "Todo o nosso ensino tende para o programa, ao passo que a vida exige estratégia e, se possível, serendipidade ${ }^{5}$ e arte". Pensar a arte com finalidade educativa, no ensino de ciências, pode ser um facilitador. Na escola, "as artes podem nos ajudar, especialmente a literatura e o cinema, que têm apresentado grandes questões da ciência no mundo moderno e contemporâneo - questões filosóficas, éticas e, sobretudo, humanas" (FERNEDA, 2017, p. 2).

Andrade, Moreira e Serra (2012, p. 114) frisam que, "atualmente, são inúmeras as iniciativas visando aproximar os campos da ciência com as diferentes formas da expressão artística". Além do mais, as Artes podem auxiliar facilitando a compreensão de conteúdos muitas vezes vistos como distantes e descontextualizados.

\footnotetext{
Meme = imitação (do grego). Resumidamente, refere-se a uma informação que se espalha rapidamente na internet, alcançando muita popularidade. Disponível em: https://www.significados.com.br/meme

5 Do inglês "serendipity": ação de descobrir coisas boas por acaso. Fonte: Dicio - Dicionário on-line de Português. Disponível em: https://www.dicio.com.br/serendipidade
} 
Considerando a potencialidade da arte, tanto no campo produtivo - uso de materiais tradicionais e das novas mídias, em interfaces intercambiáveis - quanto no campo emocional e afetivo, com arranjos singulares e diálogos inusitados entre a técnica, a estética e a poética - é possível revisitar certos conteúdos científicos (discursos e práticas), considerados densos, descontextualizados e herméticos, para torná-los mais palatáveis e mais próximos da realidade dos estudantes (ANDRADE; MOREIRA; SERRA, 2012, p. 115).

Nesse contexto, nosso objetivo é uma proposta de aula não tradicional, reunindo ciência e linguagem digital como uma expressão artística, propiciando a produção de conhecimento científico aos alunos do Ensino Médio para a profilaxia de enfermidades.

Aproximadamente dez milhões de pessoas morreram de doenças infecciosas em 2016, sendo essas responsáveis por um quinto de todas as mortes em todo o mundo (FURUSE, 2019), e a Organização Mundial da Saúde (OMS) enfatiza a importância das campanhas de educação em saúde (adaptadas à cultura e crenças locais) como a primeira forma para o controle de doenças (WHO, 2017).

Paulo Freire e Edgar Morin defendem que a educação amplie o conhecimento da realidade do mundo ao invés de escondê-la. Segundo Morin (2011), a tecnologia nos possibilita saber o que ocorre em praticamente todo o planeta ao mesmo tempo; no entanto, vivemos um paradoxo, pois, apesar dos avanços científicos do século 20 , há uma cegueira para os problemas globais, fundamentais e complexos. Para o educador francês, se desejamos conhecer o humano devemos situá-lo no universo, e não separá-lo.

O ensino de ciências pressupõe, assim, que situemos o aluno na realidade e no contexto das doenças do mundo. Paulo Freire (2016), ao enfatizar a importância do estímulo à conscientização para que nossos alunos identifiquem suas próprias realidades e, por meio da educação, busquem transformá-las, conclama também a que não nos acomodemos ante às misérias e sofrimentos alheios, elucidando os estudantes às possibilidades de modificar tristes realidades.

Diante dessas reflexões, o ensino a respeito de uma doença, como a febre amarela, pode ter numa linguagem digital de fácil trânsito - memes - uma possibilidade de diálogos em sala de aula, que se oponham às fake news ${ }^{6}$ antivacinação e que também discutam a importância do conhecimento científico.

\section{O VÍRUS DA FEBRE AMARELA}

A febre amarela é causada por um arbovírus (do inglês: arthropod-borne viroses) vírus caracterizados por serem transmitidos por artrópodes sugadores de sangue de um a outro hospedeiro vertebrado, da família Flaviviridae, que compreende cerca de 70 vírus transmitidos por mosquitos. É esse vírus, o Yellow Fever Virus (YFV), quem dá nome à família (flavus, do latim = amarelo) (NOGUEIRA; NAZARENO; SCHATZMAYR, 2009). Em termos de importância epidemiológica no Brasil, consta também desta família o vírus da dengue (NOGUEIRA; TERZIAN; RÁCZ, 2015).

Fake news = notícias falsas (do inglês). São informações que não representam a realidade, mas que são compartiIhadas na internet como se fossem verídicas. Disponível em: https://www.significados.com.br/fake-news 
O YFV é esférico, envelopado, de aproximadamente $50 \mathrm{~nm}$ de diâmetro, com RNA como material genético e algumas proteínas, como as hemaglutininas $E$ e $M$, no envelope, conforme evidencia a Figura 1.

Figura 1 - Morfologia do Vírus da Febre Amarela (YFV)

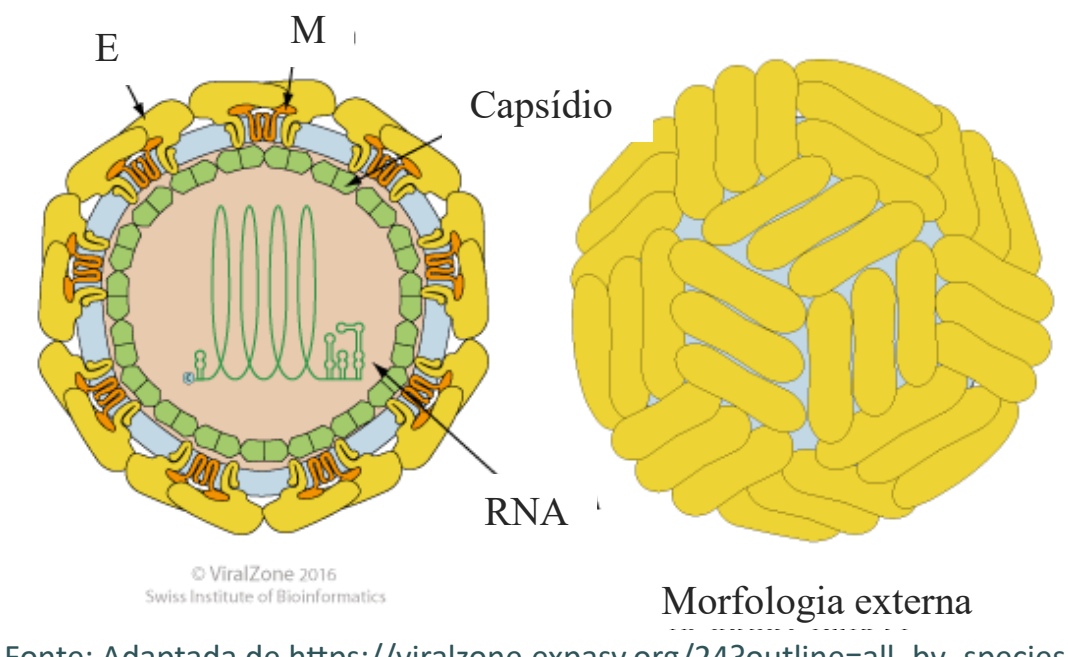

O vírus penetra na pele do hospedeiro por meio da picada da fêmea de um mosquito infectado, ocorrendo multiplicação primária em linfonodos próximos, de onde segue à circulação sanguínea, instalando-se no baço, fígado, rins, medula óssea e gânglios linfáticos. O principal acometimento é no fígado, e a morte pode decorrer de lesões necróticas nele e nos rins. No período inicial a replicação do vírus gera uma viremia (taxa de vírus no sangue) capaz de infectar outros mosquitos. Nos vetores os vírus multiplicam-se geralmente sem causar lesões ou doenças (NOGUEIRA; TERZIAN; RÁCZ, 2015).

O período de incubação é de três a seis dias e o espectro clínico varia de doença febril benigna, não específica, até fatal. Pode ser também assintomática (NOGUEIRA; TERZIAN; RÁCZ, 2015). A maioria dos pacientes recupera-se no período inicial, mas em cerca de $15 \%$ a doença progride para uma forma mais grave, havendo uma taxa de mortalidade de cerca de $20 \%$ nesses casos (BROOKS et al., 2014) e até 50\% (NOGUEIRA; TERZIAN; RÁCZ, 2015), especialmente entre crianças e idosos. Independente da gravidade não há sequelas: os pacientes ou morrem ou se recuperam por completo (ficando imunes para o resto da vida) (BROOKS et al., 2014).

\section{EPIDEMIOLOGIA DA FEBRE AMARELA}

Os arbovírus são encontrados em todas as zonas tropicais e temperadas do mundo, mas prevalecem nos trópicos pela abundância de artrópodes e animais (BROOKS et al., 2014). Quarenta e quatro países são endêmicos para febre amarela: 34 na África e 10 nas Américas (AHMED; MEMISH, 2017). No continente americano apresenta-se sob duas formas: a urbana e a silvestre, idênticas do ponto de vista etiológico e clínico, mas distintas em seus vetores (NOGUEIRA; NAZARENO; SCHATZMAYR, 2009). O vírus é mantido na natureza pela transmissão entre primatas não humanos e mosquitos hematófagos (CABRAL, 2018). 
No Brasil, a febre amarela urbana é transmitida pelos mosquitos Aedes, principalmente o Aedes aegypti, que se reproduz em águas paradas em ambientes urbanos. O mosquito torna-se infectado ao picar uma pessoa com viremia. No mosquito, o vírus multiplica-se e são necessários de 12 a 14 dias para que ele se torne infeccioso (permanecendo assim por toda a sua vida) (NOGUEIRA; TERZIAN; RÁCZ, 2015).

A febre amarela silvestre é transmitida por mosquitos Haemagogus e Sabethes, que habitam florestas úmidas, acometendo macacos. A infecção nesses animais pode ser desde inaparente até fatal (NOGUEIRA; TERZIAN; RÁCZ, 2015). Os gêneros mais suscetíveis são: Alouatta (gibão ou guariba), Cebus (macaco-prego), Ateles (macaco-aranha) e Callithrix (saguis) (CAVALCANTE; TAUIL, 2016). Os mosquitos silvestres aproximam-se de seres humanos em processos de desmatamento e/ou outras ações de desorganização ecológica, transmitindo a eles a doença também (NOGUEIRA; NAZARENO; SCHATZMAYR, 2009).

A febre amarela continua sendo um grave problema de saúde pública no continente americano, constituindo-se em uma ameaça constante nas regiões endêmicas, onde ocorre nas florestas do cerrado e nas matas de galeria ao longo de rios e também devido à possibilidade do restabelecimento de ciclos urbanos (NOGUEIRA; NAZARENO; SCHATZMAYR, 2009, p. 18).

A vigilância epidemiológica é da maior importância no controle da febre amarela, observando epizootias em primatas não humanos, casos humanos suspeitos de terem contraído a doença e a investigação epidemiológica de casos confirmados e óbitos suspeitos (NOGUEIRA; TERZIAN; RÁCZ, 2015). No Brasil, até 1999 a vigilância era pautada na ocorrência apenas de casos humanos suspeitos; a partir de então, as epizootias (casos da doença em primatas não humanos) passaram a ser vistos como evento sentinela, isto é, sinalizadores de eventual risco (CAVALCANTE; TAUIL, 2016). A expansão do número de casos de febre amarela para além da região amazônica (área endêmica), entre 2000 e 2010, ampliando a área de risco para essa doença, levou à adoção dessa e de outras estratégias de vigilância, prevenção e controle, aprimorando o sistema (BRASIL, 2016).

\section{CONTROLE E PROFILAXIA DA FEBRE AMARELA}

A única medida de controle da forma silvestre é a vacinação. Na área urbana deve ser feito também o controle do Aedes aegypti (NOGUEIRA; NAZARENO; SCHATZMAYR, 2009), que transmite, ainda, dengue, zika e chicungunha (AHMED; MEMISH, 2017). Segundo Brooks et al. (2014, p. 563), "a febre amarela continua a infectar e matar centenas de pessoas no mundo inteiro por falta de vacinação".

A vacina é feita com vírus vivo atenuado (cepa 17D, uma linhagem que perdeu sua capacidade de induzir a doença e tem sido utilizada como vacina desde 1937) e preparada em ovos embrionados. Uma única dose produz boa resposta imunológica em mais de $95 \%$ dos indivíduos (podendo haver necessidade de reforço a cada dez anos), e estima-se a persistência de anticorpos por 30 a 35 anos (NOGUEIRA; TERZIAN; RÁCZ, 2015). Ela é contraindicada para crianças com menos de 9 meses de vida, grávidas e em pessoas com alergias a ovos ou com sistema imunológico alterado (HIV com baixa contagem de linfócitos, por exemplo) (GOLDANI, 2017). No Brasil, é indicada para toda 
a população com idade acima de 9 meses nas áreas endêmicas, de transição e de risco potencial, bem como para aqueles que se dirigem a essas áreas (NOGUEIRA; TERZIAN; RÁCZ, 2015).

A vacina 17D é segura. Até 2014, mais de 400 milhões de doses haviam sido administradas e as reações adversas foram muito raras (com aproximadamente 20 casos no mundo todo, a maioria em crianças) (BROOKS et al., 2014).

\section{ASPECTOS HISTÓRICOS E GEOGRÁFICOS}

Os historiadores da ciência concordam que a febre amarela tenha atingido o continente americano por meio do tráfego marítimo (tráfico negreiro), pois tanto o vírus quanto o mosquito Aedes aegypti são de origem africana. A primeira epidemia em solo brasileiro teria sido em 1685, no Recife, e em Salvador no ano seguinte (GURGEL, 2010).

Há inúmeros relatos históricos de tentativas de controle da doença em épocas em que se desconhecia sua forma de transmissão. Gurgel (2010), por exemplo, narra que na primeira campanha sanitária oficial realizada no Recife, no fim do século 17 , havia "a obrigação de acender fogueiras com ervas aromáticas por trinta dias, emanar tiros de artilharia pelo menos três vezes ao dia, a expulsão de meretrizes, a purificação das casas" (p. 162).

Em Salvador, o recrudescimento da doença teria sido atribuído a São Francisco Xavier, que foi, assim, proclamado o padroeiro da cidade pelo Senado da Câmara (GURGEL, 2010).

O médico cubano Carlos Finlay defendeu, desde 1881, a ideia de que a transmissão se dava por mosquitos. Em 1901, Cuba atestou essa transmissão e, em 1903, Emílio Ribas, reproduzindo os experimentos cubanos, e deixando-se picar (juntamente com outros voluntários) por mosquitos Aedes aegypti contaminados, adoeceu, comprovando a transmissão no Brasil. Em 1932, Soper comprovou o ciclo silvestre, analisando a ocorrência de um surto no Espírito Santo, onde não havia o Aedes aegypti (NOGUEIRA; NAZARENO; SCHATZMAYR, 2009).

Nos anos 1950 as campanhas de erradicação do Aedes aegypti praticamente eliminaram a febre amarela urbana do continente americano, mas foram diminuindo com o tempo e o mosquito é, hoje, presente em praticamente todos os países, à exceção de Chile e Canadá (NOGUEIRA; NAZARENO; SCHATZMAYR, 2009).

\section{ATUALIDADES SOBRE A FEBRE AMARELA}

Em 2009, Nogueira, Nazareno e Schatzmayr alertaram para o potencial risco de ressurgimento de febre amarela urbana no Brasil, pelo aumento de fluxos de turismo para áreas endêmicas, pela existência de bolsões populacionais não vacinados nessas áreas, bem como pela dificuldade de operar programas de combate ao vetor em aglomerados urbanos. A febre amarela é endêmica em regiões onde existe um influxo de pessoas suscetíveis, casos de febre amarela e presença de vetor (RÁCZ, 2008), e o Brasil possui a maior área endêmica do mundo ( 5 milhões de $\mathrm{km}^{2}$, aproximadamente): nas bacias dos Rios Amazonas, Araguaia, Tocantins e Paraná (NOGUEIRA; NAZARENO; SCHATZMAYR, 2009). 
Sem casos de febre amarela urbana desde 1942 (NOGUEIRA; NAZARENO; SCHATZMAYR, 2009), o Brasil, no entanto, tem vivido, desde 2016, um considerável aumento do número de casos de febre amarela silvestre e de mortes dela decorrentes, especialmente em áreas que não eram consideradas de risco, como o Estado do Rio de Janeiro. $\mathrm{O}$ ano de 2016 já era o de maior surto dessa enfermidade nos últimos dez anos. A maioria dos casos humanos confirmados estava localizada em Minas Gerais, mas o vírus continuava a se espalhar, atingindo os Estados de São Paulo, Bahia e, especialmente, o Espírito Santo. Em janeiro de 2017 foram enviadas, pelo Ministério da Saúde, 14,3 miIhões de doses de vacinas contra a febre amarela para esses Estados, e 650 mil doses da vacina foram distribuídas em todo o país, como parte da oferta rotineira do Calendário Nacional de Vacinação (GOLDANI, 2017). Além da maior suscetibilidade imunológica, o aumento expressivo de novos casos de febre amarela pode ter ocorrido em razão de campanhas de vacinação ineficientes (CABRAL, 2018).

Segundo a Organização Mundial da Saúde (OMS), no período 2017-2018 (10/7/17 a 28/2/18) o país teve 723 casos de febre amarela, com 237 mortes, com 96 casos e 38 óbitos no Estado do Rio de Janeiro. De acordo, ainda, com a OMS, a cobertura vacinal até a metade de $2018^{7}$ estava muito aquém do planejado, tendo alcançado apenas $23 \%$ da população visada para a vacinação (ou cerca de 5 milhões e meio de pessoas, das quase 24 milhões em áreas de risco) (WHO, 2018).

Questões de saúde pública, como a que apresentamos, podem e devem estar presentes em sala de aula não apenas de Biologia, mas de forma multidisciplinar, como temas de discussões que fomentem ampliar o conhecimento dos alunos e, consequentemente, daqueles que com eles convivem, como a família e os amigos, contribuindo para um movimento de divulgação de notícias embasadas cientificamente.

\section{O MEME DE OSWALDO CRUZ NUMA SALA DE AULA DE BIOLOGIA}

Pela internet são veiculados comentários adversos à vacinação, estimulando a não imunização, alegando uma ampla gama de efeitos adversos e até letais que a vacina provocaria, ampliando o número de casos de febre amarela e de outras doenças até então controladas. Essa disseminação de notícias falsas é perigosa, pois coloca em risco não apenas a própria população que se encontra em área de risco, mas também pode permitir que a doença se alastre, chegando em áreas dantes não atingidas.

Apesar do impacto na redução de casos e mortes pelas doenças imunopreveníveis, movimentos antivacinação são cada vez mais frequentes e persuasivos nas redes sociais. Esses movimentos utilizam estratégias como distorção e divulgação de informações falsas que, alegando uma base científica, questionam a eficácia e a segurança de diversas vacinas (APS et al., 2018). Ao realizarem uma simples pesquisa na internet com o termo anti-vaccination, Aps et al. (2018) identificaram 20 páginas e 17 grupos relacionados a movimentos antivacinação, com quase 15 mil seguidores em um deles.

Os dados referem-se até à época da pesquisa. 
O mesmo termo (anti-vaccination) foi aplicado no maior site de buscas da web, que apresentou mais de seis milhões de resultados, dentre eles, diversos blogs e comunidades que apoiam a não vacinação. Isso mostra a necessidade de esclarecer a população sobre a importância das vacinas e o perigo representado pela não vacinação (APS et al., 2018, p. 3).

Os memes, segundo Guerreiro e Soares (2016), são destinados, comumente, para efeito de humor, mas envolvem ainda uma crítica social, política e cultural. Mesclam imagens das mídias com frases (de outros contextos) que, ao se complementarem, ganham esse significado (GUERREIRO; SOARES, 2016).

O desencadeamento da temática febre amarela e importância da vacinação se deu a partir do meme com a imagem de Oswaldo Cruz, em que se lê: "Não briguei com metade do Rio de Janeiro e erradiquei a varíola na cidade para você ser contra a vacinação e achar que ela faz mal" (Figura 2).

Figura 2 - Réplica do meme Oswaldo Cruz e a vacinação

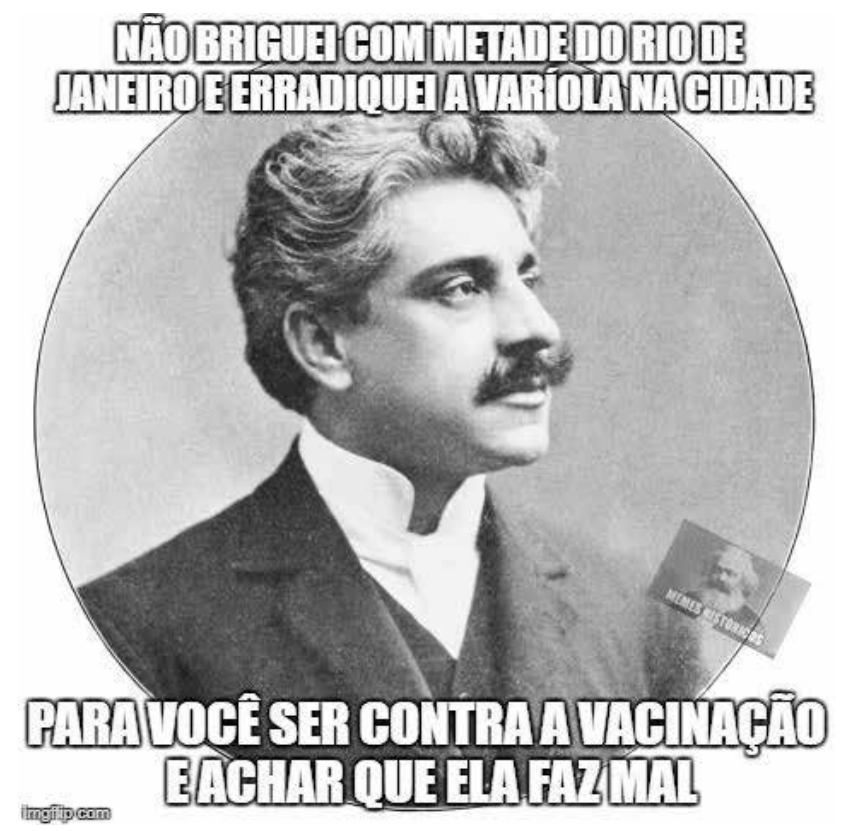

Fonte: Página do Facebook - Memes históricos. ${ }^{8}$

Esse meme foi criado/veiculado quando cresceram as postagens contrárias à vacinação, especificamente de febre amarela, em razão de casos de efeitos colaterais dela advindos em 2017.

A compreensão de um meme da maneira mais próxima daquela que objetivou seu(s) criador(es) significa orientar-se em relação a ele (ao meme), inclusive no aspecto temporal, pois no momento de produção (e de recepção) havia um sentido, e não outro, atualizando uma significação em uma esfera de possibilidades não realizadas (HORTA, 2015). A autora infere que "nenhuma interpretação já está fixada ou dada, mas apenas sugerida, dependendo, assim, o entendimento do meme das relações que ele contrai no

Disponível em: https://www.facebook.com/memesd4histori4/photos/a.370470683143535.1073741829.3701547 86508458/714988542025079/?type=3\&theater. Acesso em: 4 fev. 2018. 
contexto cultural", etc. (p. 100), e que "os memes acabaram se tornando a válvula de escape moderna para expressar a perplexidade em relação aos fatos do mundo, operando também como uma maneira de compreender esses fatos" (p. 159).

Amplamente popularizados em diversas faixas etárias, os memes costumam ser criados e divulgados em contextos humorísticos, atraindo a atenção das pessoas, e isso não é diferente com jovens e adolescentes. Aliar uma imagem pouco conhecida entre os estudantes, mas de uma figura ímpar no meio científico (Oswaldo Cruz), a uma frase que remete a um passado em que os conhecimentos científicos eram muito mais impostos do que compreendidos, contextualizando-a para os tempos atuais, pode ser uma boa opção para o ensino de doenças e a importância da imunização pela vacina.

Segundo Moacyr Scliar, Oswaldo Cruz "é não apenas o pioneiro da saúde pública em nosso país, mas o introdutor da investigação científica no Brasil" (1996, p. 224). As principais formas de atuação contra a febre amarela, quando Oswaldo Cruz era diretor-geral de Saúde Pública (o equivalente a Ministro da Saúde, nos tempos atuais), a partir de 1903, eram as chamadas "brigadas mata-mosquitos", que "percorriam a cidade, limpando calhas e telhados, exigindo providências para proteção de caixas d'água, colocando petróleo em ralos e bueiros e acabando com depósitos de larvas e mosquitos" (BATISTA, 2018, p. 19). Os doentes eram isolados ou removidos para o Hospital São Sebastião. Entre 1897 e 1906, a febre amarela matou quatro mil imigrantes no Rio de Janeiro - que ganhou a alcunha de túmulo dos estrangeiros (BATISTA, 2018). Cruz tomou como base a exitosa campanha norte-americana de combate à febre amarela realizada em Havana, baseada na transmissão pelo Aedes aegypti. $\mathrm{Na}$ época ainda não havia vacina. A 17D, em uso até hoje, foi desenvolvida somente em 1937 (BENCHIMOL, 2004).

A vacina antivariólica foi declarada obrigatória ainda no século 19, e o combate à varíola dependia do cumprimento dessa lei. Oswaldo Cruz, em junho de 1904, apresentou ao Congresso um projeto de lei restituindo a obrigatoriedade da vacinação com cláusulas rigorosas, que levavam a multas aos refratários e à exigência do atestado para matrículas em escolas, acessos a empregos públicos, entre outros (BENCHIMOL, 2004). Tais medidas culminaram na Revolta da Vacina, em novembro de 1904 - rebelião da população desconfiada da vacina e dos vacinadores e que foi esmagada pelo exército, segundo Scliar (1996). A OMS declarou a erradicação da varíola no planeta em 1979 (RÁCZ, 2015).

Foi a vacinação antivariólica, quando respeitadas as diversas fases da campanha de erradicação da doença, estabelecidas pela Organização Mundial da Saúde, que permitiu atingir o objetivo de eliminação da doença no homem (RÁCZ, 2015, p. 799).

A vacinação é a mais eficiente medida de prevenção contra a febre amarela, uma doença potencialmente grave, com alta taxa de mortalidade e para a qual não existe tratamento (BROOKS et al., 2014). Todas as faixas etárias são suscetíveis à doença (NOGUEIRA; TERZIAN; RÁCZ, 2015) e não existem fármacos antivirais para a febre amarela (GOLDANI, 2017). 
Aps et al. (2018, p. 6) ressaltam: "Dentre os riscos relacionados a vacinas, considera-se como o mais importante a não vacinação". Mesmo comprovando cientificamente um efeito deletério advindo da vacinação, a frequência é tão pequena que é inexpressiva quando comparada com os efeitos e riscos relacionados a não vacinação. Os autores alertam que: "Devido a esse fenômeno, algumas doenças previamente controladas por programas eficazes de vacinação, como sarampo, ressurgiram em populações de diferentes partes do mundo, inclusive no Brasil" (APS et al., 2018, p. 6).

Em relação à febre amarela, mais de 100 milhões de pessoas foram vacinadas na África Ocidental durante 2015. No entanto, um surto desta doença atingiu Angola e a República Democrática do Congo entre dezembro de 2015 e janeiro de 2016. Cerca de $70 \%$ dos casos ocorreram em homens. Estudos relacionaram esse surto com a alta densidade populacional aliada à baixa cobertura vacinal dos homens. No mesmo ano, foram relatados nove casos fatais de febre amarela, cinco no Brasil, todos em pessoas não vacinadas, mas em situações com recomendação da vacinação (turismo ou residentes em áreas rurais) (APS et al., 2018).

Nossa proposta foi, a partir de uma linguagem contemporânea (meme), fomentar, com alunos do Ensino Médio, discussões que pudessem levar ao aumento de conhecimentos sobre a febre amarela e sua prevenção, sensibilizando-os a respeito da importância da vacinação (e dos prejuízos dos movimentos antivacinação) e da distinção entre febre amarela silvestre e urbana.

\section{METODOLOGIA}

A metodologia planejada para o desenvolvimento desta pesquisa envolveu uma abordagem qualitativa (TAQUETTE, 2020) de intervenção, desenvolvida na primeira quinzena de fevereiro de 2018 como atividade na Semana de Acolhimento ao novo ano letivo, com três turmas de um curso Técnico em Telecomunicações Integrado ao Ensino Médio de uma instituição pública da cidade de Petrópolis, Estado do Rio de Janeiro, envolvendo cerca de 60 alunos. Na ocasião, o Brasil assistia, atônito, uma doença da época de Oswaldo Cruz alastrar-se especialmente pela região Sudeste.

A dinâmica deu-se em 2 tempos de aula de Biologia para cada turma (90 minutos), separadamente. Após a projeção do meme aos estudantes, abriu-se um debate a respeito do que eles sabiam acerca de febre amarela e da vacina, assim como do movimento antivacinação.

Após esse momento de falas, buscamos esclarecer as principais questões relacionadas a essa doença e sua profilaxia, conforme orientações do Ministério da Saúde (BRASIL, 2018). A Figura 3 retrata uma das propostas de discussão e de ponte para esclarecimentos. 
Figura 3 - Os macacos também são vítimas da febre amarela

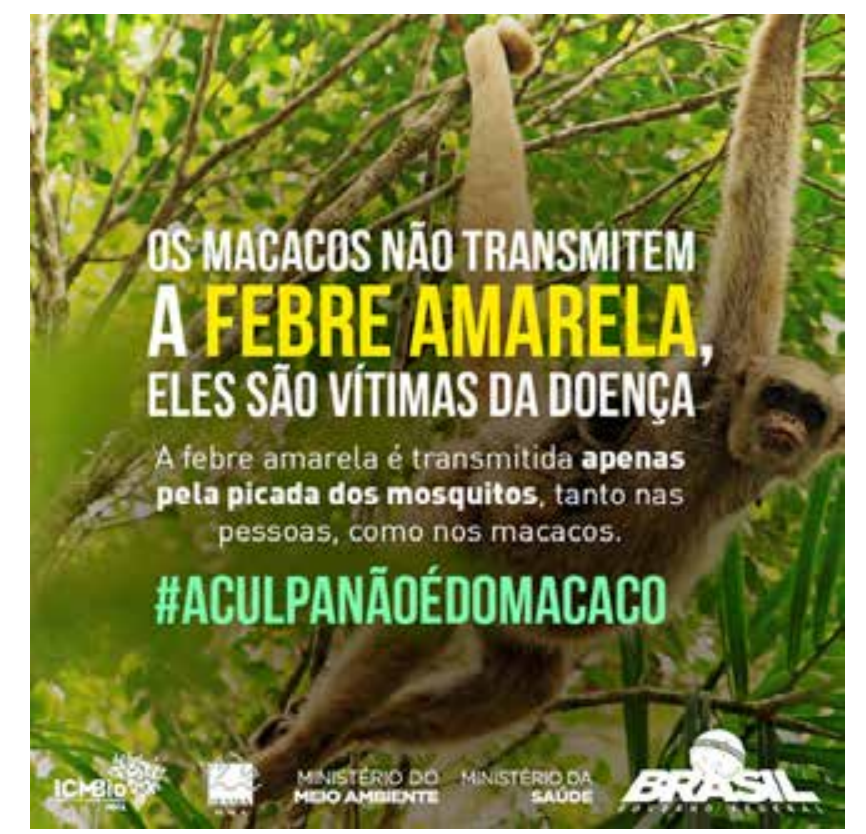

Fonte: Instituto de Tecnologia em Imunobiológicos - Fiocruz/RJ. ${ }^{9}$

Slides com informações a respeito das formas de febre amarela, meio de transmissão, vetores, principais sintomas e indicação de vacinação/áreas do país, foram utilizados para os diálogos no processo ensino-aprendizagem. Tais informações foram retiradas de artigos científicos e sites confiáveis, como o da OMS Internacional (World Health Organization - WHO). No final de cada encontro, para cada turma fizemos uma enquete a respeito de sua cobertura vacinal.

\section{RESULTADOS E DISCUSSÕES}

Com os alunos em questão, pudemos constatar que a utilização do meme de Oswaldo Cruz, referente à vacinação, se configurou como uma proposta capaz de despertar o interesse nos assuntos abordados, tais como febre amarela e vacinação. Esse recurso englobou ciência e linguagem digital com humor e fácil entendimento, proporcionando debates e produção de conhecimento científico, esclarecendo a respeito da profilaxia de doenças e fomentando a vacinação.

Quanto a um dos objetivos relacionados à discussão em decorrência do meme, do total de alunos envolvidos cinco declararam não ter se vacinado com receio de efeitos colaterais. Ressaltamos que em janeiro de 2018, em Petrópolis, houve a confirmação de um caso da doença em humanos e uma morte em macaco (epizootia).

Uma semana após a intervenção retornamos às turmas e fizemos nova enquete. Todos os alunos envolvidos declararam-se imunizados. Essa proposta corrobora a tendência mundial de prevenção de doenças por meio da educação e da sensibilização do aluno, promovendo sua conscientização (FREIRE, 2016) ante os problemas do planeta.

\footnotetext{
9 Disponível em: https://www.bio.fiocruz.br/index.php/nao-matem-os-macacos-eles-sao-aliados-da-saudeno-combate-a-febre-amarela
} 
O meme em questão pode ser um recurso sensibilizador para o ensino de febre amarela e a importância da vacinação, bem como de vários aspectos biológicos a eles relacionados, além de estudos históricos, geográficos e sociológicos (dentre outros tantos possíveis), de forma multidisciplinar. Pelo menos quatro áreas de ensinagem (ANASTASIOU; ALVES, 2015) podem ser mobilizadas e, para cada uma, há vários enfoques possíveis: Biológica (estudo do vírus da febre amarela e das espécies de mosquitos transmissores, distinção do ciclo silvestre e do ciclo urbano da doença, epidemiologia, sintomatologia e tratamento (ressaltando-se que não há, específico), além da vacinação - os casos em que é contraindicada e a polêmica a seu respeito, disseminada pelo senso comum - e das discussões dos malefícios dos movimentos antivacinação); Histórica (correlação entre o tráfico de escravos e a migração do vírus e do mosquito Aedes aegypti para as Américas, as ações de Oswaldo Cruz para o controle do Aedes aegypti no início do século 20, Oswaldo Cruz e a Revolta da vacina, no mesmo período); Geográfica (comparação entre ambientes de floresta e ambientes urbanos: os limites entre febre amarela silvestre e febre amarela urbana) e Sociológica (exclusão social e defasagem educacional e o aumento dos casos de febre amarela no Brasil nos anos 2016-2018).

No enfoque biológico, é possível trabalhar, ainda, o controle do mosquito Aedes aegypti (o mesmo vetor de dengue, zika e chicungunha, como mencionamos) a partir de características de seu ciclo biológico, com as larvas aquáticas e a correlação com água parada, além do nicho ecológico das fêmeas, hematófagas na época de postura dos ovos.

A discussão justifica-se, também, pelo fato de que, fora do meio científico, ainda persiste a ideia de que macacos (primatas não humanos) são os transmissores de febre amarela, assim como de que a vacina provoca mais mal do que a doença em si. Uma cobertura vacinal baixa compromete a população local, que permanece em risco, como também aumenta o risco potencial de disseminação para novas áreas.

\section{CONSIDERAÇÕES FINAIS}

Pesquisadores e profissionais da saúde, em todo o mundo, alertam para o aumento de doenças evitáveis com a vacinação, quando as pessoas não se vacinam ou não vacinam seus tutelados, acreditando em falsas notícias veiculadas pelos movimentos antivacinação. Com o aumento dessas enfermidades, observamos, também, o maior número de mortes delas decorrentes. Em nossa pesquisa, utilizar uma linguagem digital de fácil entendimento, com informações corretas, correspondeu a uma estratégia eficiente para combater fake news disseminadas pelas redes sociais.

Podemos inferir que, a partir do meme utilizado, os alunos se mobilizaram para obter informações científicas a respeito de uma doença (febre amarela) e da importância da vacinação. A cobertura vacinal total dos estudantes a partir da intervenção é um dado relevante, bem como os debates acerca das fake news e da responsabilidade de sua propagação. 
Aliar uma imagem pouco conhecida entre os estudantes, mas de uma figura ímpar no meio científico (Oswaldo Cruz), a uma frase que remete a um passado em que os conhecimentos científicos eram muito mais impostos do que compreendidos, contextualizando-a para os tempos atuais, é uma boa opção para o ensino de doenças e a importância da imunização pela vacina.

A estratégia adotada configurou-se como uma abordagem convidativa e motivadora ao aprendizado do aluno, para a construção do conhecimento sobre essa grave doença infectocontagiosa e sua profilaxia por meio da vacinação, de forma a propiciar uma visão consciente do mundo onde vivemos, em que esse aluno conquiste mais autonomia, aplicando os saberes desenvolvidos nas aulas de Biologia em seu próprio cotidiano.

\section{REFERÊNCIAS}

AHMED, Q. A.; MEMISH, Z. A. Yellow fever from Angola and Congo: a storm gathers. Tropical Doctor, v. 47, n. 2, p. 92-96, 2017.

ANASTASIOU, L. G. C.; ALVES, L. P. Estratégias de ensinagem. In: ANASTASIOU, L. G. C.; ALVES, L. P. (org.). Processos de ensinagem na universidade: pressupostos para as estratégias de trabalho em aula. 10. ed. Joinville: Ed. Univille, 2015. p. 73-107.

ANDRADE, L. A. B.; MOREIRA, N. dos S.; SERRA, A. do A. O cinema e o ensino de ciências: relato de uma experiência instituinte e construtiva. RevistAleph, n. 17, 2012.

APS, L. R. D. M. M.; PIANTOLA, M. A. F.; PEREIRA, S. A.; CASTRO, J. T. D.; SANTOS, F. A. D. O.; FERREIRA, L. C. D. S. Eventos adversos de vacinas e as consequências da não vacinação: uma análise crítica. Rev. Saúde Pública, v. 52 (40), p. 1-13, 2018.

BATISTA, M. H. de J. Mudanças e perspectivas teóricas no âmbito da saúde pública: a Política Nacional de Atenção Básica. 2018. 121 f. Dissertação (Mestrado Acadêmico em Ensino em Ciências e Saúde) - Universidade Federal do Tocantins, Palmas, 2018.

BENCHIMOL, J. L. Febre amarela e a instituição da microbiologia no Brasil. In: HOCHMAN, G.; ARMUS, D. (org.). Cuidar, controlar, curar: ensaios históricos sobre saúde e doença na América Latina e Caribe. Rio de Janeiro: Fiocruz, 2004. p. 57-97.

BORDENAVE, J. D.; PEREIRA, A. M. Estratégias de ensino-aprendizagem. 33. ed. Petrópolis: Vozes, 2018. BRASIL. Ministério da Saúde. Secretaria de Vigilância em Saúde. Departamento de Vigilância das Doenças Transmissíveis. Plano de contingência para resposta às emergências em saúde pública: febre amarela. Brasília: Ministério da Saúde, 2016.

BRASIL. Ministério da Saúde. Secretaria de Vigilância em Saúde. Departamento de Vigilância das Doenças Transmissíveis. Plano estratégico de vacinação contra febre amarela. Brasília: Ministério da Saúde, jan. 2018. 32 p.

BROOKS, G. F.; CARROLL, K. C.; BUTEL, J. S.; MORSE, S. A.; MIETZNER, T. A. Microbiologia médica de Jawetz, Melnick \& Adelberg. 26. ed. Porto Alegre: AMGH, 2014.

CABRAL, M. C. Reemergência de febre amarela no Estado de Minas Gerais e fatores associados. Revista Científica Fagoc-Saúde, v. 2, n. 2, p. 50-55, 2018.

CAVALCANTE, K. R. L. J.; TAUIL, P. L. Características epidemiológicas da febre amarela no Brasil, 20002012. Epidemiol. Serv. Saúde, v. 25, p. 11-20, 2016.

FERNEDA, T. Literatura e cinema no ensino de ciências: ensaio e questões para sala de aula. São Carlos: Edufscar, 2017.

FREIRE, P. Pedagogia da autonomia: saberes necessários à prática educativa. 54. ed. São Paulo: Paz e Terra, 2016.

FURUSE, Y. Analysis of research intensity on infectious disease by disease burden reveals which infectious diseases are neglected by researchers. Proc. Natl. Acad. Sci., v. 116, n. 2, p. 478-483, 2019.

GOLDANI, L. Z. Yellow fever outbreak in Brazil, 2017 [editorial]. Braz. J. Infect. Dis., v. 21, n. 2, p. 123-124, 2017.

GUERREIRO, A.; SOARES, N. M. M. Os memes vão além do humor: uma leitura multimodal para a construção de sentidos. Texto Digital, v. 12, n. 2, p. 185-208, 2016. 
GURGEL, C. Doenças e curas: o Brasil nos primeiros séculos. São Paulo: Contexto, 2010.

HORTA, N. B. O meme como linguagem da internet: uma perspectiva semiótica. 2015. 191 f. Dissertação (Mestrado) - UNB, Brasília, Portugal. Disponível em: http://repositorio.unb.br/bitstream/10482/18420/1/2015_NataliaBotelhoHorta.pdf.

MORIN, E. Os sete saberes necessários à educação do futuro. 2. ed. rev. São Paulo: Cortez; Brasília, DF: Unesco, 2011.

MORIN, E. A cabeça bem feita: repensar a reforma, reformar o pensamento. Rio de Janeiro: Bertrand Brasil, 2015.

NOGUEIRA, M. L.; TERZIAN; A. C. B.; RÁCZ, M. L. Doenças virais transmitidas por artrópodes e roedores. In: TRABULSI, L. R.; ALTERTHUM, F. Microbiologia. 6. ed. São Paulo: Atheneu, 2015. p. 829-844. Cap. 97.

NOGUEIRA, R. M.; NAZARENO, C. F.; SCHATZMAYR, H. G. Flaviviroses: dengue, febre amarela e outras doenças. In: MARCONDES, C. B. Doenças transmitidas e causadas por artrópodes. São Paulo: Atheneu, 2009. p. 9-25. Cap. 2.

RÁCZ, M. L. Poxvírus. In: TRABULSI, L. R.; ALTERTHUM, F. Microbiologia. 6. ed. São Paulo: Atheneu, 2015. p. 797-800. Cap. 93.

RÁCZ, M. L. Doenças virais transmitidas por artrópodes e roedores. In: TRABULSI, L. R.; ALTERTHUM, F. Microbiologia. 5. ed. São Paulo: Atheneu, 2008. cap. 97. p. 711-720.

SCLIAR, M. A paixão transformada: história da medicina na literatura. São Paulo: Companhia das Letras, 1996.

TAQUETTE, S. R. Ensino do método qualitativo: estudo de revisão. Millenium-Journal of Education, Technologies, and Health, n. 12, p. 25-33, 2020.

WHO. World Health Organization. Media Centre. dez. 2017. Disponível em: http: www.who.int/mediacentre/factsheets/fs107/en/. Acesso em: 14 abr. 2018.

WHO. World Health Organization. Yellow fever - Brazil - Disease outbreak News. 9 mar. 2018. Disponível em: http://www.who.int/csr/don/09-march-2018-yellow-fever-brazil/en/. Acesso em: 23 maio 2018. 